\title{
Финансовая аналитика
}

удк 336.76:338.242

\section{Биржевые индексы в товарном выражении как инструмент макроэкономического анализа}

\author{
(C) 2013 г. А.Г. Будкевич, Ян $\mathrm{Cac}^{*}$
}

Считается, что биржевые индексы отражают состояние финансово-экономической системы в целом. Однако номинальные индексы, выраженные в валюте, подвержены инфляции, что затрудняет оценку на их основе текущей макроэкономической ситуации.

В связи с этим была предпринята попытка выразить значения индексов в единицах товаров, а именно в золоте и нефти. Выбор золота и нефти в качестве товарных эквивалентов связан прежде всего с доступностью и надежностью информации о них [1-3]. Следует отдавать себе отчет в том, что и золото, и нефть не являются идеальными единицами измерения стоимости, и динамику изменения индексов в товарном выражении необходимо рассматривать в совокупности с динамикой номинальных индексов. Необходимо помнить, что между ценами на эти товары, курсом американского доллара и значениями биржевых индексов существуют сложные, неоднозначные зависимости, предполагающие в том числе и наличие обратных связей. Номинальные индексы существенно зависят от уровня цен на энергоносители, золото и другие металлы. В данной работе проводится исследование российского индекса РТС и американского Доу-Джонс [4, 5].

С одной стороны, воздействие нефтяных цен на российские индексы объясняется сырьевым характером экономики в целом. Рост цен на нефть автоматически повышает капитализацию нефтедобывающих компаний и оказывает мультипликативное воздействие на курсы бумаг прочих российских эмитентов. С другой стороны, наблюдается взаимосвязь между ценами на энергоносители и курсом американской валюты, что напрямую воздействует на биржевые индексы.

Что касается США, то, поскольку экономика страны высоко диверсифицирована, колебание нефтяных цен хотя и отражается на американском фондовом рынке, воздействие это разнонаправлено.

Связи между ценой на золото и биржевыми индексами являются не менее сложными. С одной стороны, обвалы биржевых котировок вызывают ощутимый рост цен на золото, поскольку инвесторы стремятся «переложиться» в более надежные активы, а именно в драгоценные металлы. С другой стороны,

* Будкевич А.Г. - канд. экон. наук, проф. каф. промышленного менеджмента НИТУ «МИСиС».

Сас Ян - канд. экон. наук, проф. Краковской горнометаллургической академии. изменение цен на золото влияет на покупательную способность американской валюты, а следовательно, и на оценку всех финансовых инструментов.

Расчет товарных эквивалентов проводится по следующей формуле:

$$
I_{\text {тов }}=\frac{I_{\text {долл }}}{P_{\text {тов }}}
$$

где $I_{\text {тов }}$ - значение эквивалента индекса, номинированного в товарном выражении;

$I_{\text {долл }}$ - официальное значение индекса на конкретную дату;

$P_{\text {тов }}$ - текущая цена соответствующего товара в долларах США.

Начальная капитализация индекса РТС составляла 12,666 млрд долл. США, что соответствовало начальному значению индекса в 100 пунктов.

В данной работе предлагается условно считать стартовую капитализацию равной 100 долл. (т.е. 1 пункт приравнять к одному доллару). В этом случае эквивалент индекса РТС будет показывать, какое количество товара можно приобрести в текущий момент на сумму, соответствующую 100 долл. США, вложенную в индекс в сентябре 1995 г. Подобным методом были просчитаны «нефтяной» и «золотой» эквиваленты индекса за период с начала 2008 по апрель 2013 г. Аналогичная методика предлагается для проведения расчетов по индексу Доу-Джонса.

Данные о среднемесячных значениях индексов и текущих ценах на нефть и золото принимали по материалам официальных сайтов [3, 6, 7].

Для того чтобы оценить и сравнить динамику индекса в долларах с динамикой индексов в товарном выражении, необходимо представить показатели в относительном виде. За 100 \% принимали значение каждого из индексов на январь 2008 г.

На рис. 1 представлена динамика относительных значений индекса РТС, номинированного в долларах, унциях золота и баррелях нефти. На данном графике видно, что в период с января 2008 до лета 2008 г. (в предкризисной стадии) номинальный индекс РТС продолжал формальный рост, «золотой» эквивалент не демонстрировал выраженной тенденции, а «нефтяной» эквивалент сигнализировал о нарастающих сложностях в экономике. В период кризиса с лета 2008 до осени 2009 г. все три показателя изменились синхронно и значительно упали. Видно, что «нефтяной» эквивалент опережает сам индекс, потому что российская экономика существенно зависит от цен на нефть. Безусловно, реак- 


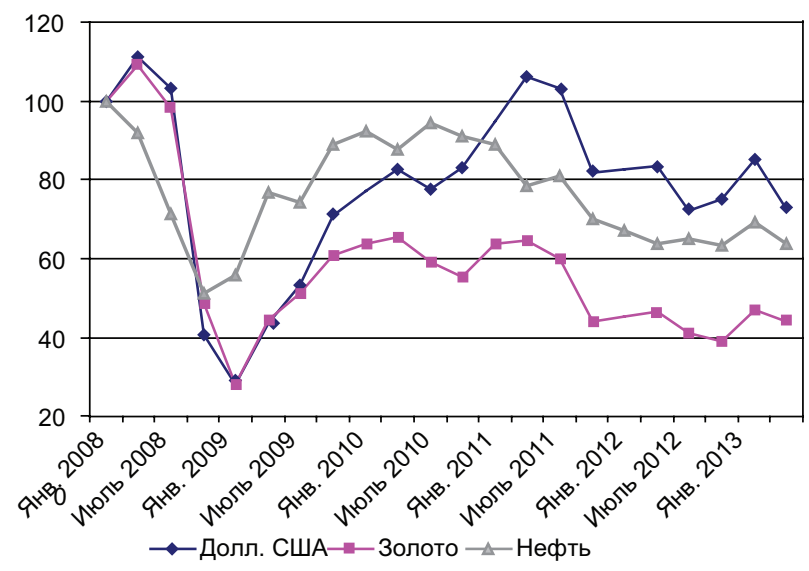

Рис. 1. Динамика относительных значений индекса РТС, номинированного в долларах, унциях золота и баррелях нефти, \%

ция не мгновенная, она немного запаздывает. Что касается золота, то его эквивалент следует за номинальным индексом, поскольку инвесторы, видя падение номинального индекса, должны некоторое время обдумать ситуацию и переложиться в золото.

С первых месяцев 2010 г. начался период преодоления кризиса. Индекс в это время устойчиво рос и к лету 2011 г. формально вернулся на уровень января 2008 г. В дальнейшем индекс опустился ниже докризисных значений, более того - наблюдается нисходящий тренд (находится в интервале от 40 до $70 \%$ от докризисных значений).

На рис. 2 представлена динамика относительных значений индекса Доу-Джонса, номинированного в долларах, унциях золота и баррелях нефти (выражены в процентах от уровня января 2008 г.).

На графике можно выделить также три области. В период с января 2008 до лета 2008 г. (в предкризисной стадии) индекс Доу-Джонса практически не изменялся, «золотой» эквивалент также не демонстрировал выраженной тенденции, а «нефтяной» эквивалент очень резко упал и указывал на нарастающие сложности в экономике. В период кризиса с лета 2008 г. до конца осени 2009 г. все три показателя изменились. Нефтяной эквивалент показывал выраженную тенденцию роста. Это связано с тем, что цена на нефть стремительно падала. Номинальный индекс и золотой эквивалент продолжали падение.

С начала 2010 г. наблюдается период преодоления кризиса. Индекс в это время стабилизировался, устойчиво рос и постепенно, возвращаясь к своим прежним позициям, стал близок к значениям 2008 г. «Золотой» эквивалент установился ниже значений докризисных в связи с ростом цен на золото. «Нефтяной» эквивалент постепенно вернулся к значениям 2008 г. и, более того, продемонстрировал восходящий тренд.

Сопоставление индексов РТС и Доу-Джонса позволяет сделать выводы о том, что экономика США восстановилась гораздо быстрее и сейчас наблюдается выраженная тенденция роста. Экономика России постепенно восстанавливалась после кризиса, но с лета 2011 г. опять наметилось ухудшение ситуации.

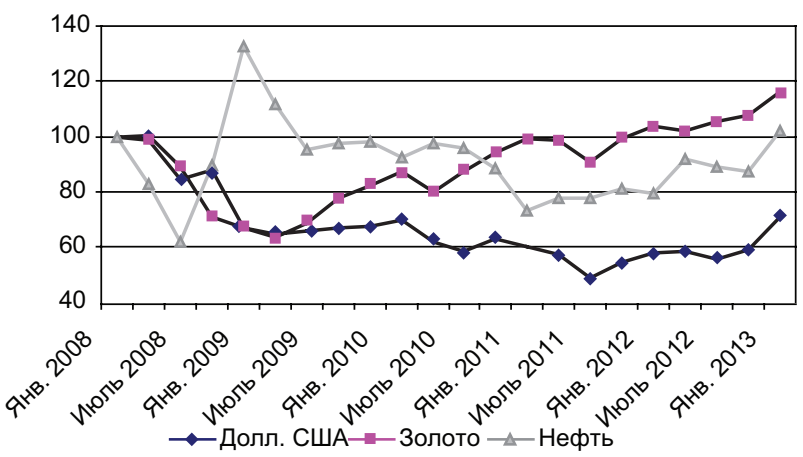

Рис. 2. Динамика относительных значение индекса ДоуДжонса, номинированного в долларах, унциях золота и баррелях нефти, \%

Анализ двух графиков позволяет предположить, что в России ситуация с привлечением финансовых ресурсов будет ухудшаться на фоне снижения внутреннего потребления. В подтверждение данного предположения можно отметить, что сокращение внутреннего потребления снижает интерес инвесторов к экономике РФ, а вероятный рост зарубежных экономик отвлечет финансовые ресурсы на зарубежные рынки.

Что касается США, то, вероятно, американская экономика будет расти. Наряду со снижением внутреннего спроса в РФ будет ощущаться рост спроса на сырьевые товары на Западе.

В ходе данных исследований была использована методика перевода индексов в товарные эквиваленты, которая ни в коем случае не должна заменить уже существующие номинальные индексы, а только дополняет их и позволяет более объемно оценить макроэкономическую ситуацию.

В дальнейшем аналогичным образом планируется расширить, дополнить и провести анализ по другим индексам, в частности отраслевым. Используя метод перевода индекса в товары, можно с более высокой достоверностью оценивать состояние экономики страны в целом и предсказывать, каким будет положение в будущем.

\section{Библиографический список}

1. Динамика цен на золото - URL: www.news.yandex.ru/gotes/10htm (дата обращения: 26.06.2013).

2. Динамика цен на нефть - URL: www.signalrp. ru/cena-na-neft.html (дата обращения: 26.06.2013).

3. Обзоры цен на нефть и металлы - URL: http:// fx-commodities.ru/ (дата обращения: 26.06.2013).

4. Информация о финансовых рынках - URL: http://www.finam.ru/ (дата обращения: 24.06.2013).

5. Информация о торгах на российской бирже URL: https://www.micex.ru/ (дата обращения: 24.06.2013).

6. Официальный сайт индекса RTS - URL: http:// rts.micex.ru/ (дата обращения: 21.06.2013).

7. Официальный сайт индекса Доу-Джонса URL: http://www.dowjones.com/ (дата обращения: 21.06.2013).

8. Будкевич А.Г. Биржевые индексы в товарном выражении // «Экономика в промышленности» 2011. № 4. C.112-114. 